\title{
CARACTERIZACIÓN FITOQUÍMICA DEL EXTRACTO HIDROALCOHÓLICO DEL FRUTO DE Bromelia pinguin Y EVALUACIÓN DE SU ACTIVIDAD ANTIFÚNGI- CA FRENTE A UN HONGO AISLADO DEL FRUTO DE CACAO (Theobroma cacao L.) EN ESTADO DE PUDRICIÓN.
}

\author{
Phytochemical Characterization of the Hydro-Alcoholic Extract of the Fruit of Bromelia pinguin \\ and Evaluation of Their Antifungal Activity Against an Isolated Fungus From Cacao (Theobroma \\ cacao L.) in State Rot
}

$\mathrm{T}$

Andrés Felipe Lugo Vargas 1 , Daniela TarráJaramillo2, María Natali Nieto Guzmán3 y JhonIronzi Maldonado Rodríguez4*

\begin{abstract}
1,2,4Grupo BPNA del Programa de Química., Facultad de Ciencias Básicas, Universidad de la Amazonía, Campus Porvenir calle 17 Diagonal
17 con carrera 3F-Barrrio Porvenir 3Laboratorio de Fitopatología del centro de investigaciones Amazónicas SINCHI
\end{abstract}

\section{RESUMEN}

Se evaluó el efecto antifúngico del extracto hidroalcohólico de fruto de B. pinguin frente a un hongo aislado de frutos enfermos en estado de pudrición de Cacao (Theobroma cacao L.) mediante un ensayo de inhibición de crecimiento micelial empleando el método de dilución en agar. El extracto tuvo un efecto antifúngico bastante notorio en un rango de concentraciones entre 2,5 y $10 \%(\mathrm{~V} / \mathrm{V})$ y se pudo evidenciar además una fuerte relación dosis-respuesta. Un análisis fitoquímico preliminar, permitió identificar flavonoides, antraquinonas, taninos, saponinas y glucósidos cardiotónicos como los principales metabolitos secundarios presentes en el extracto hidroalcohólico de B. pinguin; sin embargo, aquí se discute sobre la Pinguinaína, como principal responsable de dicha actividad.

Palabras Clave: B. pinguin, pinguinaina, $M$. roreri, Moniliasis, extracto hidoralcohólico, Cacao

\begin{abstract}
The antifungal effect of hydroalcoholic extract of $B$. pinguin fruit against an isolated fungus from diseased fruits cocoa (Theobroma cacao L) in state rot, by an inhibition assay using the method mycelial growth agar dilution. The extract had a remarkable antifungal effect in a range of concentrations between 2.5 and $10 \%(\mathrm{~V} / \mathrm{V})$ and could also show a strong dose-response relationship. A preliminary phytochemical analysis identified flavonoids, anthraquinones, tannins, saponinas and cardiac glycosides as the main secondary metabolites present in the aqueous alcoholic extract of B. pinguin; however, it is discussed on the Pinguinaína, as the main responsible for the activity.
\end{abstract}

Palabras Clave: B. pinguin, pinguinaina, M. roreri, Moniliasis, extracto hidoralcohólico, Cacao 


\section{INTRODUCCION}

Uno de los grandes problemas que afrontan a nivel mundial los cultivadores de Cacao (Theobroma cacao L.) son las infecciones causadas por hongos fitopatógenos como Moniliophthora roreri, Ceratocystis fimbriata, Collectotrichum gloesporoides, Crinipellis perniciosa, hongos del complejo Phytophthora, entre otros, que pueden generar pérdidas hasta del $100 \%$. En Colombia el hongo fitopatógeno Moniliophthora roreri es causante de la enfermedad denominada Moniliasis o pudrición acuosa que puede causar pérdidas hasta del $90 \%$ de la producción de Cacao. Los fungicidas de síntesis química para el control de $M$. roreri no son del todo satisfactorios o son inconsistentes de año a año, y su alta frecuencia de uso está asociado a la contaminación ambiental y a mayores costos de producción que resulta antieconómico para el cacaotero (1). El manejo de estas enfermedades se basa en la integración de prácticas agronómicas como la tecnificación, la reducción del inóculo primario, la siembra de clones de alta productividad y la implementación permanente de prácticas de saneamiento y de manejo cultural; sin embargo, la poca capacitación a los productores y sus bajos recursos económicos para implementarlos hacen difícil su implementación (2).

Los plaguicidas naturales han sido usados en la agricultura como una alternativa para el manejo de problemas fitosanitarios y muestran ventajas; por ejemplo, en su mayoría son biodegradables y no afectan la salud del hombre ni la del medio ambiente (3). Lo anterior permite generar un interés permanente en la búsqueda de plaguicidas naturales. y en este aspecto, las plantas representan un potencial enorme ya que contienen principios activos los cuales extraídos en forma adecuada y administrados en dosis suficientes, producen efectos insecticidas o fungicidas que permiten el manejo de insectos-plaga y de microorganismos fitopatógenos (4), (5).

Bromelia pinguin L. (Bromeliaceae) es una planta ampliamente distribuida en toda América central y el caribe, conocida como Piñuela, Maya, o Piña de ratón (6), (7), (8). El fruto es comestible aunque ocasiona irritación ligera en los labios sin efectos nocivos y también pequeños dolores ulcerosos sobre los dedos de las personas quienes manipulan su pulpa aunque de carácter reversible (9). Además de ser considerado como un posible alimento funcional (10), su fruto ha sido usado en fitoterapia como antihelmíntico y para tratar la tosferina y el escorbuto (11). También es considerado como una fuente rica en proteasas, especialmente pinguinaina; esta última, considerada un preparado proteico cuya composición podría ser variable (9), (11).

Varios estudios han mostrado evidencias sobre la actividad antibacteriana y fungitóxica del fruto de $B$. pinguin frente a distintas cepas de hongos y bacterias; sin embargo, aún no existen estudios que pretendan establecer algún tipo de actividad frente a patógenos fúngicos de Cacao (Theobroma cacao L.). En este sentido el objetivo de este trabajo fue investigar sobre la posible actividad fungicida que podría tener un extracto hidro-alcohólico de fruto de $B$. pinguin frente a un hongo aislado de frutos enfermos en estado de pudrición de Cacao, y además establecer mediante un análisis fitoquímico preliminar, el contenido de sus principales metabolitos secundarios.

\section{METODOLOGIA}

\section{Obtención del material vegetal.}

El material vegetal constituido por el fruto de $B$. pinguin $L$. fue obtenido en una zona rural cercana al municipio de Florencia en el departamento del Caquetá-Colombia, en el mes de septiembre del año 2015. Los frutos fueron cortados en trozos pequeños y sometidos a secado en estufa eléctrica a $43 \pm 2{ }^{\circ} \mathrm{C}$ durante 4 días consecutivos y posteriormente fue pulverizado en un molino convencional, obteniéndose $2385 \mathrm{~g}$ de material vegetal.

\section{Obtención del extracto hidroalcohólico.}

El material pulverizado se sometió a un proceso de sucesivas extracciones por maceración con etanol al $75 \%$ hasta agotar matriz. Luego de cada extracción el material vegetal fue filtrado mediante vacío usando papel filtro Whatman No. 1y el filtrado se concentró a presión reducida para eliminar el alcohol. Posteriormente dicho filtrado se dejó durante un mes a temperatura ambiente y tapado con papel aluminio al cual se le hicieron pequeños orificios para permitir al eliminación de cualquier vestigio de etanol en la muestra, obteniéndose finalmente $60 \mathrm{~mL}$ de un líquido relativamente denso y de color café oscuro (Extracto hidroalcohólico). Este extracto se almacenó a temperatura ambiente en un tubo plástico con tapa-roscadebidamente rotulado para los posteriores análisis químicos 
Transcurrido este tiempo, y con la ayuda de unaaguja de disección estéril se inoculó en todo el centro de la caja de Petri una fracción del hongo de 15 días de crecimiento y cada caja fue mantenida en estufa para cultivos a 26 o $\mathrm{C}$ durante un periodo de 12 días. Como control positivo en lugar de extracto se adicionó al medio de cultivo el fungicida comercial de amplio espectro Ridomil ${ }^{\circledR}$ (Metalaxyl-M + Mancozeb) en una concentración de 500 ppm. El control negativo consistió en el hongo creciendo en medio de cultivo sin ningún aditivo adicional o extracto.

\section{Medición del crecimiento.}

El crecimiento del hongo fue seguido mediante registro fotográfico y las mediciones de crecimiento radial se hicieron a partir del cuarto día, justo cuando el control negativo alcanzó su crecimiento completo en la caja de Petri, hasta el día 7.

\section{RESULTADOS Y DISCUSIÓN}

Tabla 1. Análisis fitoquímico preliminar del extracto hidroalcohólico de Bromelia pinguin

\begin{tabular}{|c|c|}
\hline $\begin{array}{c}\text { Tipo de metabolito } \\
\text { secundario }\end{array}$ & Resultado \\
\hline Flavonoides & + \\
\hline Leucoantocianidinas & - \\
\hline Antraquinonas & + \\
\hline Taninos & + \\
\hline Cumarinas & - \\
\hline Alcaloides & \pm \\
\hline Saponinas & + \\
\hline Glucósidos cardiotónicos & + \\
\hline Esteroides y/o triterpenos & \pm \\
\hline
\end{tabular}

$+=$ Presencia, $-=$ Ausencia, $\pm=$ No concluyente

Como puede apreciarse en la tabla 1, el extracto hidroalcohólico de Bromelia pinguin mostró la presencia de flavonoides, taninos, saponinas,antraquinonas, y glucósidos cardiotónicos, en tanto que las pruebas para alcaloides, triterpenos y esteroides no fueron concluyentes. A pesar de los pocos estudios fitoquímicos reportados; metabolitos como flavonoides, taninos y cumarinas, terpenos y saponinas ya han sido descritos para esta planta (20), (21), (10), mientras que para los alcaloides y glucósidos cardiotónicos aún no existe reporte alguno. Es bien sabido que la composición y contenido de metabolitos presentes en una planta puede variar de acuerdo a condiciones geo gráficas, clima, suelo,estado vegetativo de la planta al momento de recolección y también debido a posiblesvariaciones genéticas de la planta (22). De igual manera, las pruebas negativas o poco concluyentes para el caso de cumarinas y terpenos respectivamente, pueden estar asociadas también a la baja concentración de estos constituyentes en el extracto y la poca sensibilidad del método para ser detectados. Para el caso de alcaloides se sabe también que ciertos grupos en moléculas de proteínas pueden dar falsos positivos.

\section{Actividad antifúngica.}

Con respecto a la actividad antifúngica se pudo evidenciar que el extracto hidroalcohólico de Bromelia pinguin posee un efecto inhibitorio sobre el crecimiento in vitro del patógeno fúngico que genera la pudrición del fruto de Theobroma cacao L. En la figura 3 se muestra un registro fotográfico del crecimiento del hongo durante 7 días en la cual se puede observar claramente un efecto inhibitorio el cual además es dependiente de la dosis. Para concentraciones de extracto mayores de $10 \% \mathrm{~V} / \mathrm{V}$ no se observó crecimiento luego de 7 días de incubación, mientras que a dosis menores su crecimiento fue notorio y a partir del cuarto día ya se observaban diferencias significativas de crecimiento radial entre las concentraciones de extracto evaluadas, y entre éstas y los respectivos controles.

Los mismos resultados mostrados en la figura3pero expresados en términos de porcentaje de inhibición de crecimiento radial en la tabla 2 permiten observar una inhibición del $100 \%$ del crecimiento radial a una concentración de extracto de $10 \% \mathrm{v} / \mathrm{v}$ o mayores y sin efecto significativo o ningúno (0-9,3\% de inhibición) a concentraciones de extracto de 0.6 $\% \mathrm{v} / \mathrm{v}$ o menores. Se ha reportado que en ensayos de efectividad biológica para cualquier fungicida un $70 \%$ de inhibición es considerado aceptable (23) y en este experimento dicha inhibición corresponde a una concentración alrededor de $5 \% \mathrm{v} / \mathrm{v}$ de extracto. Estos resultados aunque alagadores no son del todo novedosos, pues no es la primera vez que se reporta actividad antifúngica para el fruto de $B$. pinguin. Ya en años anteriores se había descrito una significativa actividad antifúngica del extracto de pulpa del fruto de esta planta frente a Trichophyton mentagraphytes y T. rubrum (24), incluso, un estudio reciente ha demostrado que B.pinguin inhibe la población de hongos y bacterias en suelos donde esta planta crece (8). Del fruto También existen reportes sobre la actividad anti 
bacteriana frente a varias cepas patogénicas humanas (10).

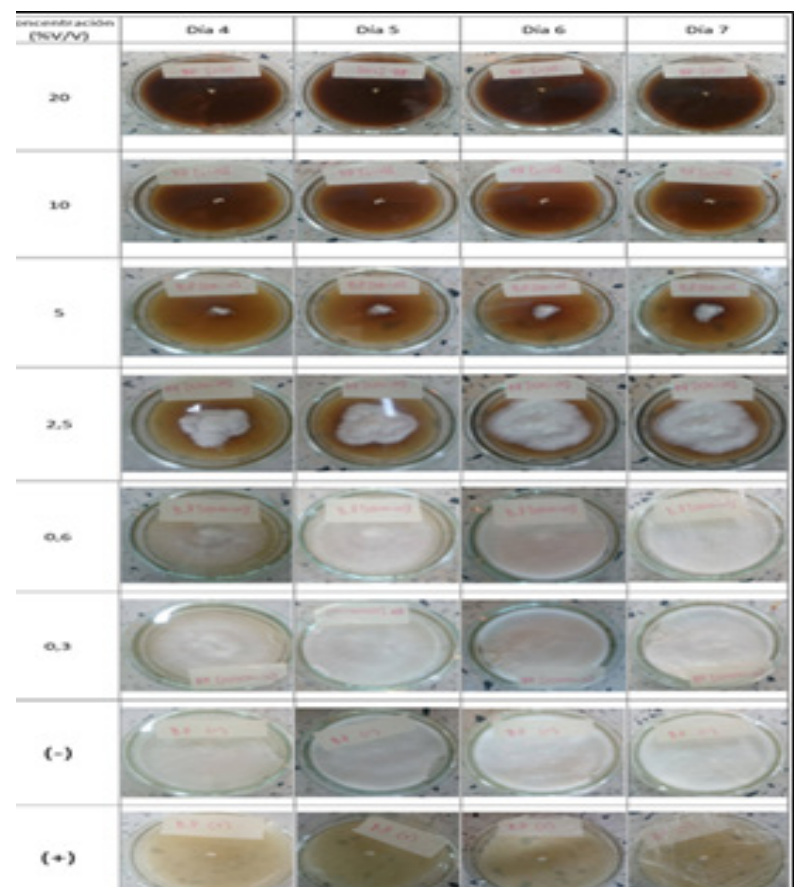

Figura 1.Registro fotográfico del crecimiento de patógeno fúngico frente a distintas concentraciones de extracto de Bromelia pinguin
Sin embargo, hay que considerar aquí la presencia en $B$. pinguín de enzimas proteasas, en particular la pinguinaína, un pre parado enzimático con actividad proteolítica presente en el fruto de esta especie la cual ya ha sido blanco de diferentes estudios (27), (28), (29), (9), (30).

Dicha enzima podría ser la responsable de la actividad antifúngica frente al patógeno fúngico que afecta el fruto de Theobroma cacao L. encontrada en este estudio. Además de la amplia diversidad estructural de los metabolitos secundarios con efecto antifúngico, también se han descrito proteínas antifúngicas (25), (31), (32), e incluso se han caracterizado algunas a partir de plantas (33) (34) y otros organismos (35), (36), (37), (38).

Múltiples mecanismos de acción antifúngica podrían estar involucrados en la inhibición de esta enzima sobre el patógeno fúngico que genera la pudrición del fruto de Theobroma cacao L., como por ejemplo estar atravesando la membrana e interferiendo en la síntesis de ADN, y ARN. También podría estar inhibiendo la cadena respiratoria celular o disminuyendo el ATP

Tabla 2. Inhibición del crecimiento del hongo frente al extracto hidroalcohólico de B. Pinguin (Resultado promedio de tres mediciones)

\begin{tabular}{|c|c|c|c|c|}
\hline $\begin{array}{c}\text { Concentración de } \\
\text { extracto (\% V/V) }\end{array}$ & Dia 4 & Dia 5 & Dia 6 & Dia 7 \\
\cline { 2 - 5 } & \% de inhibicion & \% de inhibicion & \% de inhibicion & \% de inhibicion \\
\hline 20 & 100 & 100 & 100 & 100 \\
\hline 10 & 100 & 100 & 100 & 100 \\
\hline 5 & 83,8 & 80 & 76,8 & 76 \\
\hline 2.5 & 46,6 & 34,9 & 28 & 26 \\
\hline 0,6 & 9,3 & 4,7 & 2 & 0 \\
\hline 0,3 & 2,4 & 2,4 & 0 & 0 \\
\hline Control positivo & 100 & 100 & 100 & 100 \\
\hline \hline
\end{tabular}

La lista de metabolitos secundarios que han mostrado actividad antifúngica es tan amplia como su diversidad estructural o el espectro de actividades biológicas que algunos de ellos muestran y es por esto que sería muy apresurado establecer con exactitud una relación entre el efecto inhibitorio mostrado por el extracto hidroacohólico de $B$. pinguin y alguno de sus metabolitos presentes. Flavonoides, saponinas, alcaloides, terpenos y muchos otros han sido reportados muchas veces haciendo mención sobre sus actividades antifungicas (25), (26).
(39); o podrían estar alterando la permeabilidad de la membrana formando poros y ocasionando la pérdida de iones y otros solutos (40). También podría estar hidrolizando o interferiendo en la síntesis de componentes esenciales de la pared celular como la quitina, el quitosán, entre otros (41). De cualquier manera, establecer la responsabilidad de la pinguinaina en la inhibición in vitro de $\mathrm{M}$. roreri al igual que algunos de estos u otros mecanismos de acción requerirá de otros estudios. Actualmente en nuestros laboratorios se llevan a cabo experimentos de inhibición con el preparado enzimático tanto in vitro como in vivo. 


\section{.3. CONCLUSIONES}

Por primera vez se estudió la actividad antifúngica frente a un hongo aislado de frutos enfermos de Cacao (Theobroma Cacao) del extracto hidroalcohólico de B. pinguin del Caquetá, región Amazónica Colombiana, encontrándose un significativo efecto inhbitorio sobre el crecimiento micelial del hongo, que es además dependiente de la dosis. Los resultados obtenidos y los antecedentes de $B$. pinguin señalan a la Pinguinaína como la principal responsable de la actividad, considerando sin embargo que es necesario llevar a cabo otros estudios para tratar de resolver esta hipótesis. De igual forma se están llevando a cabo otros ensayos para identificar el hongo.
Los autores agradecen sinceramente a la Vicerrectoría de Investigaciones de la Universidad de la Amazonía, al Profesor Armando Sterling Cuéllar, a la profesora Claudia Gonzales y su grupo de auxiliares de laboratorio, y a todas aquellas personas que hicieron posible la realización de este estudio.

Con respecto a los grupos de alimentos y la frecuencia de suministro en la dieta de los preescolares, se evidenció que los grupos más importantes eran suministrados a diario, tal es el caso de las frutas y las verduras, los cereales, las carnes y leguminosas y los lácteos. Si bien el consumo de los azucares y las grasas se limitan en el adulto, el niño puede comerlos a diario sin sobrepasar las porciones recomendadas según la edad, en este aspecto las madres aseguraron limitar su consumo a 1 o 2 veces por semana (63\%).

\section{AGRADECIMINETOS}

\section{BIBLIOGRAFIA}

1. Phillips M. W, Coutiño A, Ortiz C.F, López A. P, Hernández J. \&Aime M. C. First report of Moniliophthoraroreri causing frosty pod rot (moniliasis disease) of cacao in Mexico. Plant Pathol. 2006, 55:584. 2. López B.O, González M.O, Ramírez G.S.I, Lee R.V, Ramírez G.M.B, Alvarado G.A. \& Gehrke V.M. Diagnóstico y técnicas para el manejo de la moniliasis del cacao. Universidad Autonóma de Chiapas; Universidad Pedagógica y Tecnológica de Colombia. Impreso: Digitall. 2006, Tuxtla Gutiérrez, Chiapas, México. 40p.

3. Vergara R. De la agricultura tradicional a la agricultura biológica. Memorias Seminario Regional. 1997, Universidad Pedagógica y Tecnologica de Colombia.

4. Hernández L. A.N, Bautista B. S. \& Velázquez V. M.G. Prospectiva de extractos vegetales para controlar enfermedades en Poscosecha. Revista Fitotecnia Mexicana 2007, 30 (2): 119-123.

5. Barrera N. L.\& Bautista B. S. Actividad antifúngica de polvos, extractos y fracciones de Cestrumnocturnum L. sobre el crecimiento micelial de Rhizopusstolonifer (Ehrenb.:Fr.) Vuill. Revista Mexicana de Fitopatología 2008, 26:27-31.

6. Payrol J. A, Mosquera D. G, Meneses A, Cruz M.D, Banze F, Martínez M. M, López O.R. Determinación de Parámetros Farmacognósticos y Bromatológicos y Evaluación de la Actividad Antiparasitaria de una Preparación obtenida del Fruto de BromeliapinguinL. que crece en Cuba. Acta Farm. Bonaerense 2005a., 24(3): 377-382.

7. CONABIO, Catálogo taxonómico de especies de México. 1. In Capital Nat. México. CONABIO, 2009, Mexico City.

8. Looby C. I. and Eaton D. W. Effects of Bromeliapinguin (Bromeliaceae) on soil ecosystem function and fungal diversity in the lowland forests of Costa Rica. BMC Ecology 2014, 14:12.

9. Payrol A. J, Obregón D. W, Natalucci L. C, Caffini O. N. Reinvestigation of the proteolytically active components of Bromeliapinguin fruit. Fitoterapia 2005b, 76, 540-548.

10. Pio L. J. F, López A. G, Paredes L. O, Beltrán U. M, Díaz C.P.S, Delgado V. F. Physicochemical, Nutritional and Antibacterial Characteristics of the Fruit of Bromeliapinguin L. Plant Foods Hum Nutr. 2009, 64:181-187.

11. Looby C, Hauge B.J, Barry D, Eaeton D.W. Fungal inhibition by Bromeliapinguin (Bromeliaceae) and its effect on nutrient cycle dynamics. Tropical Ecology 2012, 53 (2): 225-234.

12. Domínguez X. A, Balick M. J, Cicció J. F, Joel D. M, Marbach I, Mayer A. M. \& Hilton J. J. Métodos de investigación fitoquímica (No. 581.19072 D671). Centro Regional de Ayuda Técnica, México, 1973, DF (México).

13. Sanabria G. A. Análisis fitoquímico preliminar: metodología y su aplicación en la evaluación de cuarenta plantas de la familia Compositae. Universidad Nacional de Colombia. Facultad de Ciencias. Departamento de Farmacia. 1983, Santafé de Bogota. 


\section{Revista de Investigaciones - Universidad del Quindío}

14. Bilbao M. R. Análisis fitoquímico preliminar. Universidad del Quindío, Armenia-Quindío, Colombia. 1997,180

15. Martínez M. Manual de prácticas de laboratorio de farmacognosia y fitoquímica. 2008, Universidad de Antioquia, Medellín-Colombia.

16. Suárez C. L. Y. Aislamiento e identificación de Moniliophthoraroreri causante de la moniliasis en municipios del nororiente Colombiano y ensayos preliminares para su control biológico. Revista respuestas - Universidad Francisco de Paula Santander, 2006, 11(1): 3-8.

17. Villavicencio M. y Jiménez M. Caracterización morfológica, fisiológica y patogénica de Moniliophthoraroreri aislados de cinco provincias de la costa ecuatoriana. Artículos de tesis de grado - FIMCP, 957. 2010, ESPOL, Ecuador.

18. Sánchez M. F. D. y Garcés F.F.R. Moniliophthoraroreri (Cif y Par) Evans et al. en el cultivo de cacao. Scientia agropecuaria, 2012, 3(3): 249 - 258.

19. Phillips M. W, Castillo J, Krauss U, Rodriguez E. y Wilkinson J. M. Evaluation of cacao (Theobroma cacao) clones against seven Colombian isolates of Moniliophthoraroreri from pathogen genetic groups. Plant pathology, 2005, 54: 483-490.

20. Payrol J. y Miranda M. Estudio farmacognóstico de BromeliaPinguin L. (piña de ratón). Rev. Cubana de farm., 2000, 34(3): 181-186.

21. Payrol J, Miranda M. y García J. Extracto etéreo de frutos de BromeliaPinguin L. (piña de ratón) por el sistema acoplado CG-EM. Rev. Cubana de farm., 2001, 35(1): 51-55.

22. García C. Y, Díaz N. A, Oyola C. L.L. Brango V. J, Castaño O. J.C, Maldonado J.I. Estudio fitoquímico preliminar y de actividad antimicrobiana de la especie Lippia alba originaria del Piedemonte Amazónico. Mom. Cien. 2014, 11(2):75,82.

23. Pérez A.R, García E. S.R, Carrillo F. J. A, Angulo E. M.A, Valdez T. J. B, Muy R. M. D, García L. A. M, Villareal R. M. Control de Cenicilla (SphaerothecafuligineaSchlechtend: Fr, Pollaci) con Aceites Vegetales y Sales Minerales en Pepino de Invernadero en Sinaloa, México. Revista Mexicana de Fitopatología 2010, 28 (1): 17-24.

24. Camacho H. I. L, Chavez-Velazquez J. A, Uribe-Beltran M.J, Rios-Morgan A, Delgado-Vargas F. Antifungal activity of fruit pulp extract from Bromeliapinguin. Fitoterapia 2002, 73: 411-413.

25. Montes B. R, Cruz C. V, Martínez M. G, Sandoval G.G, García L. R, Zilch D. S, Bravo L. L, Bermúdez T. K, Flores M. H. E, Carvajal M. M. Propiedades antifúngicas en plantas superiores. Análisis retrospectivo de Investigaciones. Revista Mexicana de Fitopatología 2000, 18 (2):125-131.

26. Montes B. R. Diversidad de compuestos químicos producidos por las plantas contra hongos fitopatógenos. Revista Mexicana de Micología 2009, 29: 73-82.

27. Toro G. E, Maretzki A. y Matos M. Isolation, purification, and partial characterization of pinguinain, the proteolyticenyzme from Bromelia penguin. Archives of biochemistry and biophysics, 1968, 126: 91-104.

28. Toro G. E. y Rodríguez I. Immunochemical studies on pinguinain, a sulfhydryl plant protease. Archives of biochemistry and biophysics, 1976, 175: 359-366.

29. Toro G. E, Rodríguez I. y Ehrig H. Structural studies on pinguinain, changes induced by carboxamidomethylation. Biochimicaet Biophysica Acta, 1980, 622: 151-159.

30. Payrol J, Obregón W, Trejo S. y Caffini N. Purification and characterization of four new cysteine endopeptidases from fruits of BromeliapinguinL. grown in Cuba. Protein J., 2008, 27:88-96.

31. Upadhyay A. y Srivastava S. Characterization of a new isolate of Pseudomonas fluorescensstrain Psd as a potential biocontrol agent. Lett. Appl. Microbiol. 2008, 47: 98-105.

32. Yan R, Hou J, Ding D, Guan W, Wang C, Wu Z. y Li M. In vitro antifungal activity and mechanism of action of chitinase against four plant pathogenic fungi. J. Basic Microbiol. 2008, 48: 293-301.

33. Chu K.T, Liu K.H. y Ng T.B. Cicerarin, a novel antifungal peptide from the green chickpea. Peptides. 2003, 24: 659-663.

34. Ng T.B, Parkash A. y Tso W.W. Purification and characterization of-and-benincasins, arginine/ glutamate-rich peptides with translation-inhibiting activity from wax gourd seeds. Peptides. 2003, 24: 11-1 35. Yang L, Tan R.X, Wang Q, Huang W. y Yin Y. Antifungal cyclopeptides from HalobacilluslitoralisYS3106 of marine origin. Tetrah. Lett. 2002, 43: 6545-6548.

36. Tomie T, Ishibashi J, Furukawa S, Kobayashi S, Sawahata R, Asaoka A, Tagawa M. y Yamakawa, M. Scarabaecin, a novel cysteine-containing antifungal peptide from the rhinoceros beetle, Oryctes rhinoceros. Biochem. Biophys. Res. Commun. 2003, 307: 261-266. 
37. Gomes V. M, Carvalho A. O, Da Cunha M, Keller M. N, Bloch Jr. C, Deolindo P. y Alves E.W. Purification and characterization of a novel peptide with antifungal activity from Bothropsjararacavenom. Toxicon. 2005, 45(7): 817-27.

38. Meyer V. A. Small protein that fights fungi: AFP as a new promising antifungal agent of biotechnological value. Appl. Microbiol. Biotechnol. 2008, 78: 17-28.

39. Cociancich S, Ghazi A, Hetru A, Hoffman J.A. y Letellier L..Insect defensin, an inducible antibacterial peptide, forms voltage-dependent channels in Micrococcus luteus. J. Biol. Chem. 1993, 268: 19239-19245.

40. Thevissen K, Terras F.R.G. y Broekaert W.F. Permeabilization of fungal membranes by plant defensins inhibits fungal growth. Appl. Env. Microbiol. 1999, 65: 5451-5458.

41. Odds F.C, Brown A.J.P. y Gow N.A.R. Antifungal agents: mechanisms of action. TrendsMicrobiol. 2003, 11: 272-279. 